\title{
Appendix 3
}
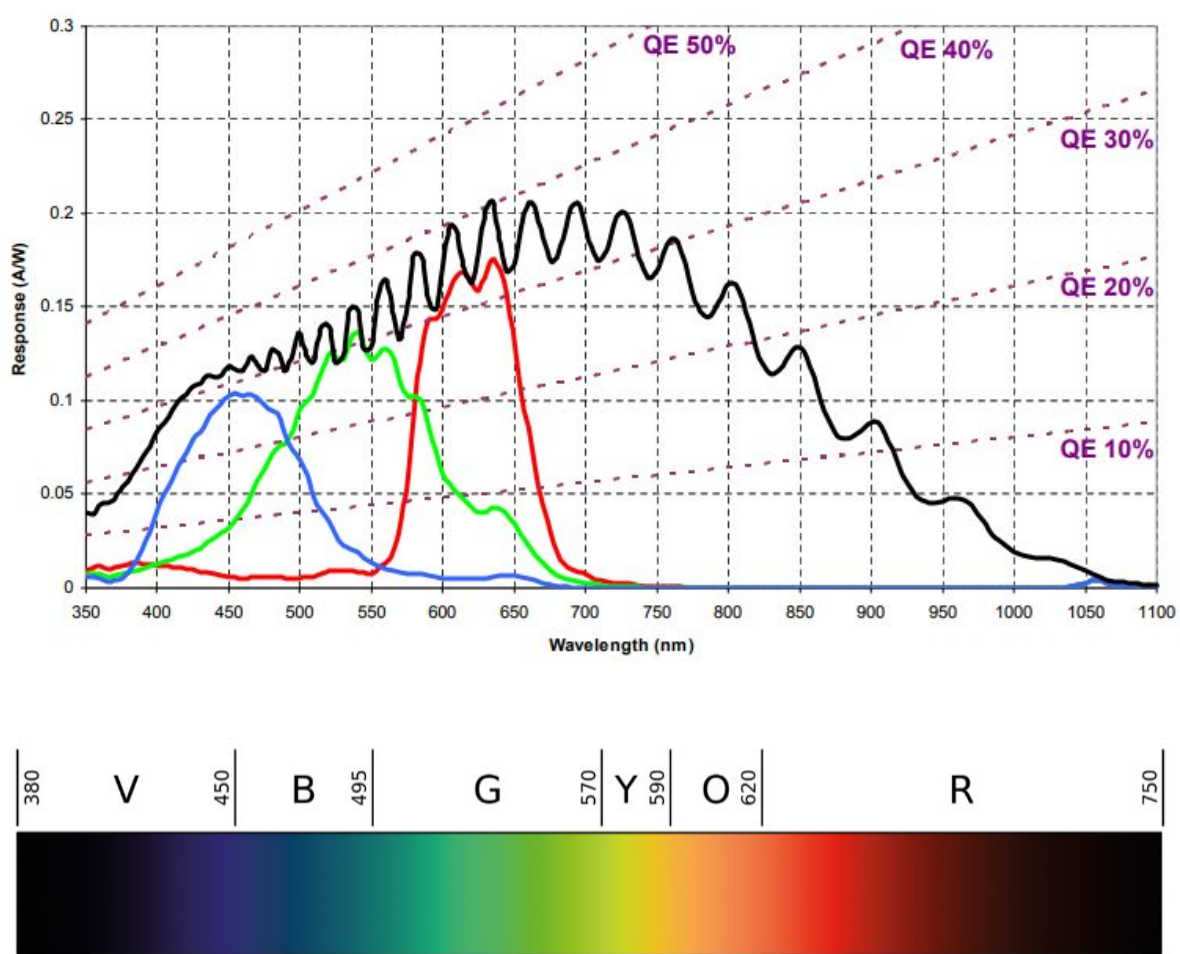

Fig. 1. Color and spectral response curve of the high speed camera 